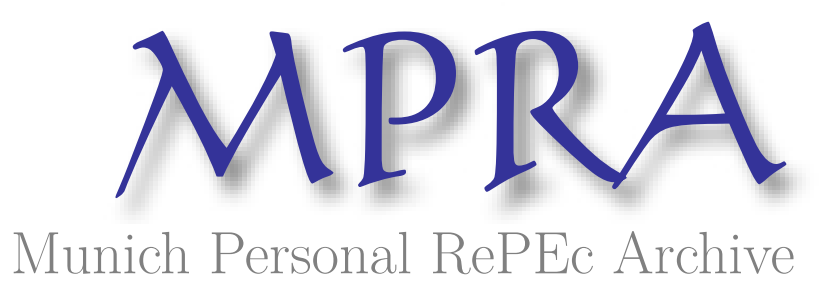

\title{
What Are the Effects of Expanding Social Pension on Health? Evidence from the Basic Pension in South Korea
}

\author{
Pak, Tae-Young \\ Sungkyunkwan University
}

7 April 2020

Online at https://mpra.ub.uni-muenchen.de/103794/

MPRA Paper No. 103794, posted 28 Oct 2020 11:30 UTC 


\title{
What Are the Effects of Expanding Social Pension on Health? Evidence from the Basic Pension in South Korea*
}

\author{
Tae-Young Pak ${ }^{\dagger}$
}

\begin{abstract}
Non-contributory social pension has been widely used to provide minimum income support for disadvantaged seniors. Despite its efficacy in reducing old-age poverty, only a few studies systematically assessed whether the benefits of social pension extend to health outcomes. In this paper, we exploit a reform to the South Korean social pension in 2014 to provide evidence on the health effects of expanding social pension. Using data from the Korean Longitudinal Study of Aging, we estimate a series of differencein-differences models that compare changes in health of individuals age-eligible for the social pension (age $\geq 65$ ) to those younger than the minimum qualification age (age $<65$ ), before and after the reform in 2014. The estimates show an average of 8.1$9.0 \%$ reductions in the count of depressive symptoms attributable to the reform. We also find that the mental health benefit comes primarily from beneficiaries being more satisfied with their financial condition and overall quality of life. However, despite the large increase in income there were no significant improvements in grip strength and self-rated health. Overall, this study highlights the importance of social pension as a means of protecting mental health of disadvantaged seniors.
\end{abstract}

Keywords: old-age poverty; non-contributory pension; depression; financial satisfaction; South Korea

JEL Classification Codes: H5, I31, I38, J14

${ }^{*}$ Acknowledgement: The author would like to thank the editor and two anonymous reviewers as well as seminar participants from American Council on Consumer Interests Annual Conference, Association for Public Policy Analysis \& Management Annual Conference, and Population Association of America Annual Meeting for valuable feedback.

${ }^{\dagger}$ Assistant Professor, Department of Consumer Science, Sungkyunkwan University, Address: 50503 Hoam Hall, Sungkyunkwan University, Seoul, South Korea, Phone: +82-2-760-0526, E-mail: typak@skku.edu. 


\section{Introduction}

Social Security systems in the U.S. and many other high-income countries have built upon a contributory scheme in which a fixed proportion of the labor income is taxed to support the system. In countries where the labor market informality is high, however, a traditional pay-as-you-go pension could not fully scale-up and left a large proportion of the population without pension coverage (van Ginneken, 1999). In response, a growing number of countries have introduced social pension or supplementary income support. Social pension is a government-provided cash transfer in which access to benefits does not require a contributory record. The provision/expansion of social pension has proved to be an efficient way to alleviate the depth of poverty as well as its incidence among older persons (Barrientos and Lloyd-Sherlock, 2002; Deaton and Case, 1998; Kaushal, 2014).

An important, yet underexplored, hypothesis is whether more generous social pension program leads to better health. From a public health perspective, the provision of pension income can enable the poor to avoid exposure to harmful environments and adopt practices beneficial to health (Phelan et al., 2010). For instance, beneficiaries would be able to use pension income to move to a safer or cleaner living environment, upgrade household facilities for better sanitation, or consume nutritious meals that they need to maintain good health (Case, 2004). For those who have forgone medical care due to cost-related reasons, additional cash benefit would afford an opportunity whereby the desired level of healthcare consumption can be achieved (Lloyd-Sherlock and Agrawal, 2014). Moreover, increases in non-labor income promote a transition into retirement, which allows individuals to move away from hazardous and stressful working environments. The argument that retirement improves health is particularly relevant to low-income workers who were engaging in risky and heavy physical work before retirement (Kuhn, 2018).

While the positive impact pension support has on health seems theoretically validated, the magnitude of the effect is contingent on a number of potentially offsetting factors. The first is the extent to which additional pension income increases the consumption of unhealthy goods (e.g., alcohol, candies, drugs, and tobacco). Social pension is primarily the income support program in which benefits can be spent on any goods, including essential and non-essential ones. Under the plausible assumption that income elasticity with respect to unhealthy goods is positive, cash transfer through social pension could promote unhealthy behaviors and partially offset the health benefits realized through the channels mentioned above.

A negative social image associated with government support is another pathway that could contract beneficiaries' health and well-being (Stuber and Schlesinger, 2006). Social 
stereotype tends to discriminate against people on government support, labeling them a failure, lazy, and burden to society (Krause, 1996). A link between government support and emotional discomfort among beneficiaries has been well reported in psychiatric research (Dooley and Prause, 2002; Qi and Wu, 2018).

Empirical studies regarding health-social pension correlation have yielded mixed results. Of the slim evidence to date, pension income was found to have a positive influence on selfrated health in households' pooling income (Case, 2004) or to reduce depressive symptoms among poor rural populations (Galiani et al., 2016; Salinas-Rodríguez et al., 2014). In China, pension provision to rural residents improved physical health but had no discernible impact on self-rated health and psychological well-being (Cheng et al., 2018). Evidence from Colombia (Hessel et al., 2018) showed a positive association between cash transfer and self-rated health in disadvantaged older men, but not in women. A randomized experimental study by Aguila et al. (2015) demonstrated that a significant portion of income supplement was spent on doctor visits and medications, leading to improvements in lung function, memory, and hemoglobin levels of beneficiaries. Despite some evidence of health benefits, findings from this line of research vastly differ in terms of health outcomes and the characteristics of beneficiaries examined.

This study delves into the social pension expansion in South Korea (Korea, hereafter) and its impact on population health. One of the major social problems for Korea has been a large number of seniors entering retirement without pension income, contributing to the highest rate of elderly poverty among OECD countries. To address this issue, the Korean government introduced a social pension scheme in 2008. This program was further expanded in July 2014 in an attempt to provide monthly benefits that are large enough to mitigate elderly poverty, particularly for the generation not covered by the compulsory national pension. In this paper, we study the spillover effects of the 2014 social pension expansion on health of beneficiaries. We conduct a series of difference-in-differences analysis that compares prevs. post-expansion changes in health outcomes of the eligible group relative to the noneligible group. The 2014 expansion presents a unique opportunity to isolate the causal effect of social pension because the potential beneficiary group was changed unexpectedly as the reform was implemented. This setting enables us to minimize the confounding effect of voluntary consumption changes in anticipation that income will rise permanently.

Results showed that the 2014 expansion of the Korean social pension was associated with significant reductions in the count of depressive symptoms and the prevalence of clinical depression, holding other covariates constant. It also suggested that increased satisfaction with financial condition and overall quality of life is the primary mechanism the reform has produced mental health benefits. Other pathways, such as retirement, changes in health 
behavior, and increased access to healthcare, were found to have a limited mediating role. Furthermore, there was no evidence that other health domains, with regard to measures of grip strength and self-rated health, were improved in response to the reform. Our findings indicate significant mental health benefits and a likely decline in suicide among disadvantaged seniors, given a close link between depression and suicidal behaviors among poor elders in Korea.

This study makes several contributions to the literature on the health effect of social pension. First, we demonstrate improvements in mental health resulting from a declining prevalence of major depression. Our analyses below show that the estimated pension effect is not merely picking up a transient mood change but also capture a meaningful reduction in clinical depression, which will have an important implication for mortality benefits. Second, we provide evidence for the health effect of social pension in a relatively well-developed country. Currently, most existing evidence in this strand of research has been reported from developing countries in which health benefit of cash transfer is likely to arise from curing disease associated with poverty and insanitation (e.g., infectious and communicable disease). In our study, we look into the case of a developed economy where people are more likely to suffer from relative poverty and die with "diseases of affluence" like cancer and suicide. Third, our analyses demonstrate an alternative pathway through which social pension expansion could yield health benefits, namely a subjective well-being channel. This finding complements the existing evidence of health gains through increased access to health care and nutrition reported in developing countries (Aguila et al., 2018).

\section{Background}

\subsection{Basic Old-Age Pension in South Korea}

The National Pension Scheme (NPS) is the primary social security program in Korea. It was launched in January 1988 and provided compulsory coverage to regular employees in workplaces with ten or more employees. The program has been gradually expanded to include all workplaces and became the universal pension for the general public in 2006 (Lee and Lee, 2009). Although participation has been mandated by law since 1999, a large number of self-employed and non-regular workers were exempted. Therefore, the share of NPS contributors in working-age populations has remained below $50 \%$ since its inception (Jones and Urasawa, 2014).

Beginning in January 2008, the Korean government introduced a means-tested income support program for the elderly, the Basic Old-Age Pension (BOAP). It is a tax-funded social 
pension that transfers flat-rate cash benefits to qualified individuals. Pension benefits are means-tested based on the applicant's age and recognized household income (income plus income-equivalent wealth). ${ }^{1}$ Eligibility is granted to those aged 65 or higher whose recognized household income is in the bottom $70 \%$ of the distribution. The maximum benefit was set at $5 \%$ of the average monthly pension income earned by NPS participants for three years before implementing the program. In 2008, beneficiaries could receive a maximum of 84 thousand KRW (\$78) per month if single and 139 thousand KRW (\$129) if married. ${ }^{2}$ The total number of beneficiaries increased to 3.7 million in 2010 and 4.9 million in 2014 - about $67-68 \%$ of the age-eligible population (Lee and Wolf, 2014).

As of July 2014, the BOAP was replaced by the Basic Pension (BP). This reform was originated from a former president Park's electoral pledge to provide a new pension program that pays out 200 thousand KRW $(\$ 186)$ every month to all seniors aged 65 or higher. Once elected, the Park's administration executed this pledge in the form of doubling monthly allowances from the BOAP and re-naming the program into the BP. However, amid criticisms that the BP will be insolvent within a few decades, the government re-instated the income testing rule and limited coverages to the poorest $70 \%$ of the age-eligible seniors. Under the $\mathrm{BP}$ scheme, beneficiaries could collect up to $10 \%$ of the average pension benefits from the NPS, which is equivalent to 168 thousand KRW (\$156) for singles and 269 thousand KRW (\$250) for married couples.

The introduction of the BP included a clause to consider benefits from public transfer programs when calculating recognized income. That is, under the BP monthly benefit was reduced by the amount of transfer income from other social welfare programs or contributory pension. For an unmarried person entitled to National Basic Livelihood Security (NBLS), for instance, the expected maximum benefit from the BP was 168 thousand KRW minus benefits from the NBLS. Despite these rules, doubling maximum benefits was a significant improvement over the previous scheme for those without a source of fixed income stream.

Empirical research into the effect of BOAP on economic security has provided mixed results. Some studies found that poverty headcount and poverty gap were lower for households with basic pension beneficiaries (Lee and Moon, 2014), or that beneficiaries were more likely to avoid the poverty trap (Kang and Choi, 2010). In contrast, others found that disposable income and consumption expenditures did not increase much for beneficiaries (Lee and Jang, 2015), or that improvement in financial well-being in response to the BOAP was small in

\footnotetext{
${ }^{1}$ The recognized household income is current income plus annuity value of net worth, which is determined by the formula: $(0.7 \times($ monthly labor income -84 thousand KRW $))+$ miscellaneous income $+(0.04 \times$ net assets). In 2010, for instance, the maximum recognized income to qualify for the BP was 700 thousand KRW for singles and 1120 thousand KRW for married couples.

${ }^{2}$ As of June 9th, 2018, a thousand KRW is equivalent to $\$ 0.931$.
} 
magnitude (Lee and Kwon, 2016; Shin and Do, 2015). Moreover, studies have disagreed as to whether the BOAP reduced labor supply and to what extent replaced private transfer from adult children to parents. Lee et al. (2019) found no changes in labor income and private transfer income after the 2014 reform, while Lee and Lee (2009) found a moderate correlation between the BOAP and private transfer among middle-income families.

Prior literature attributed this mixed evidence to the small amount of monthly benefits. However, given a low coverage of contributory pension and the high rate of old-age poverty in Korea, it is difficult to imagine that a new source of pension income has created little welfare benefits. A plausible explanation for the limited efficacy of the BOAP is the confounding effect of the 2007-2008 financial crisis. The fact that the program was implemented near the peak of the 2007-2008 financial crisis raises the possibility that the recession may have affected poor seniors to a greater extent and through this pathway partially offset the correlation between the BOAP and beneficiaries' financial condition. Indeed, recent research on the 2014 reform demonstrated a declining poverty gap and a significant rise in consumption expenditures and subjective well-being among those who benefited from the reform (Lee et al., 2019; Pak, 2020a; 2020b). We extend this line of research by examining whether the 2014 reform had a spillover effect on health outcomes.

\section{$3 \quad$ Research Design and Methods}

\subsection{Data description}

The data are drawn from the 2008 to 2016 waves of the KLoSA, a biennial longitudinal survey of individuals aged 45 or older and their spouses. The KLoSA provides information on demographic characteristics, family structure, health and health behaviors, labor market participation, and economic conditions that are critical to understanding living circumstances of older Korean persons. Interview has been administered in the second half of every even year. In 2014, the survey was conducted between September and November (after implementation of the BP reform).

The sample is restricted to individuals aged 55 to 74 years in 2014. Additionally, to avoid the potentially confounding effects a cigarette tax increase in January 2015 we excluded individuals who identified themselves as smoker in the 2014 survey. The final sample is an unbalanced panel of 16,430 observations for 3792 individuals. ${ }^{3}$

\footnotetext{
${ }^{3}$ The estimation results in the following section are robust to the choice of age bands and keeping smokers in the sample.
} 


\subsection{Treatment and control group}

The means-tested structure of social pension poses an empirical challenge for randomizing treatment assignment. Potential beneficiaries around the income or asset threshold have an incentive to spend down their assets to qualify for cash support (Hubbard et al., 1995), as demonstrated by a positive association between welfare eligibility and consumption expenditures (Gruber and Yelowitz, 1999; Powers, 1998). If changes in wealth are endogenously determined by a means test, enrollment status at the time of the BP reform cannot be used as a treatment condition.

The alternative approach is to use the minimum qualification age $(\geq 65)$ as a threshold to become age-eligible for the BP (Koh and Yang, 2017). ${ }^{4}$ Under this identification strategy, non-married respondents aged 65-74 and married couples where the eldest spouse is aged 65-74 get assigned to the treatment group, and non-married persons aged 55-64 and married couples where both spouses are aged 55-64 form the control group. This approach identifies "intent-to-treat" effect and yields a lower bound estimate of the policy effect.

\subsection{Measures of physical and mental health}

\section{Self-rated health}

Self-rated health is a global measure of health that captures a full range of possible diseases and functional limitations (Idler and Benyamini, 1997). It is based on the survey question, "How would you rate your health condition at present?". ${ }^{5}$ Responses are scaled from 1 to 5, with "very poor" health equal to 1 and "very good" health equal to 5 . Close to $81.2 \%$ of the sample respondents rated their health condition fair or better.

\section{Grip strength}

Grip strength is known to indicate the risk of developing chronic diseases and mortality in old age (Silventoinen et al., 2009). It is considered a better marker of frailty than chronological age (Syddall et al., 2003) and has been used as a proxy of general health conditions in geriatric research (Christensen et al., 2001). The strength was measured using a hand-held dynamometer; respondents were asked to squeeze a lever as hard as they can, and the measurements were recorded in kilograms on a scale of 0 to 100. Of a total of four measurements

\footnotetext{
${ }^{4}$ The threshold age does not coincide with a full retirement age for the National Pension in South Korea (equivalent to Social Security in the US), which had been 55 until December 2015 and increased to 60 from January 2016. Adding an indicator of retirement age to regressions does not alter our inferences about the pension effect.

${ }^{5}$ Survey questions are translated from Korean.
} 
for each respondent (two for each hand), the mean of the largest recorded value for each hand was taken. This measure has advantages over self-rated health as its values are independent of reporting style and are measured on a clearly defined scale (Decker and Schmitz, 2016).

\section{Mental health}

Mental health is measured by the Center for Epidemiologic Studies Depression (CESD) scale. The CES-D is a reliable measure of depression and anxiety, which shows high correlations with clinical diagnoses (Turvey et al., 1999). The test is based on a series of questions on negative feelings (having the blues, experiencing life as a failure, feeling lonely or sad, crying), positive thoughts (being hopeful about the future, feeling happy, enjoying life), somatic activities (losing appetite, suffering from a restless sleep, talking less), and social contacts (experiencing other persons as unfriendly). The KLoSA uses CES-D10 and yields a score of depression on a 0-30 scale.

\section{Estimation strategy}

The health effect of the BP is estimated by comparing changes in health outcomes of the treatment groups and the control groups before and after the reform in 2014. We estimate a linear difference-in-differences (DD) model in the following form,

$$
y_{i, t}=\beta_{0}+\beta_{1} I\left(\text { Age }_{i, t} \geq 65\right)+\beta_{2} \text { Post }_{t}+\beta_{3} I\left(\text { Age }_{i, t} \geq 65\right) \times \text { Post }_{t}+X_{i, t}^{\prime} \Psi+\tau_{t}+\varepsilon_{i, t}
$$

, where $i$ denotes individual respondent; $t \in\{2008,2010,2012,2014,2016\}$ indexes survey years; $\varepsilon_{i, t}$ is an error term; and $\beta$ and $\Psi$ are parameters to be estimated. The outcome variable, $y_{i, t}$, is one of the health indicators for person $i$ at time $t$. $I\left(A g e_{i, t} \geq 65\right)$ is an indicator of treatment group, and Post $t_{t}$ is a dummy for observations from the 2014 and 2016 waves. $\tau_{t}$ denotes year-of-survey dummy, which accounts for heterogeneity in health by time. The treatment effect of the BP reform is identified by $\beta_{3}$ on the interaction term between $I\left(\right.$ Age $\left._{i, t} \geq 65\right)$ and Post $_{t}$.

The covariate vector $X_{i, t}$ includes age, age squared, gender, educational background, marital status, number of children, public health insurance ownership, national pension receipt, social welfare receipt, household income, total net worth, cohort fixed effects, and monthof-survey fixed effects. Education background is captured by binary variables for less than middle school education and for high school or college education (less than elementary school education forms the reference category). For marital status, we include dummies for married, divorced or separated, and widowed (with never-married forming the reference group). We also define a dummy for welfare benefit receipt, which takes on one for respondents receiv- 
ing benefits from unemployment compensation, industrial accident compensation, national basic livelihood security program, Veterans benefits, and other social welfare programs (not including the BP), and zero otherwise. Household income is the total amount of income received by both spouses in the year preceding the survey, not including benefits from the BP and social welfare programs. Total net worth is defined as the sum of checking and savings accounts, bonds, stocks, private savings, personal lending to others, vehicles, housing, real estate, business, and other financial assets minus short-term debts and mortgages. Household income is transformed by $\log (x+1)$, and total net worth is transformed by the log-modulus function (John and Draper, 1980). ${ }^{6}$ Cohort fixed effects are captured by dummies for the year of birth (1931-40; 1941-50; 1951-60; 1961+).

Regression equations are estimated by pooled ordinary least squares (OLS). It has advantages over the individual fixed effects (FE) model in that it captures changes in health of persons who aged from 64 to 65 during the reform (2012 to 2014), as well as those who were already older than age 65 when the BP was expanded. In our sample, about $90 \%$ of respondents in the treatment group were aged 65 or higher in 2012, and only less than $10 \%$ turned the threshold age at the time of the reform. The individual FE model is limited in that it does not reflect improvements in health among those who were already collecting benefits from the BP prior to the reform and leads to a significantly underestimated policy effect.

Standard errors are clustered at the individual and age levels to account for nonindependence of errors within person $\times$ age groups. As the levels at which standard errors should be clustered are not clear, we present regression results with alternative standard errors clustered at the combination of individual, household, age, year, and sampling stratum levels (Table A1). The standard error estimates vary across specifications but leave the inference of the BP effect unchanged.

A key identifying assumption is that there is no discrepancy in the underlying trend in health outcomes unrelated to the BP expansion. That is, changes in health should be reasonably similar for the treatment and control groups in the absence of the BP effect. A formal test of parallel trends is to examine the joint significance of interaction terms between the treatment condition and year dummies in the pre-expansion periods. The following regression is used to implement this test.

$$
y_{i, t}=\gamma_{0}+\gamma_{1} I\left(\text { Age }_{i, t} \geq 65\right)+\sum_{t=2008}^{2016} \gamma_{2, t} \cdot \tau_{t}+\sum_{t=2008}^{2016} \gamma_{3, t} I\left(A g e_{i, t} \geq 65\right) \cdot \tau_{t}+X_{i, t}^{\prime} \Phi+\varepsilon_{i, t}
$$

\footnotetext{
${ }^{6}$ The formula for $\log$-modulus transformation is, $\operatorname{sign}(x) \times \log (|x|+1)$. This transformation applies standard logarithmic transformation to negative values while preserving the location of zero. The interpretation of marginal effects remains the same.
} 
The null hypothesis is that there is no underlying trend differential in health between the two groups before the BP expansion $\left(H_{0}: \gamma_{3,2008}=\gamma_{3,2010}=0\right)$. If the null hypothesis is rejected, the study would conclude that unobserved factors drove a trend break in health, and a different identification strategy should be sought.

The weakness of age-based identification is that the treatment group includes both enrollees and non-enrollees aged 65 or higher. Since the average treatment effect is dispersed across non-enrollees (about 30\% of the treated subjects), the estimate of $\beta_{3}$ in eq. (1) understates changes in health due to the BP expansion. To account for this downward bias, we estimate the instrumental variable (IV) model of the following form.

$$
y_{i, t}=\delta_{0}+\delta_{1} \widehat{\operatorname{TrInc}}_{i, t}+\delta_{2} I\left(\text { Age }_{i, t} \geq 65\right)+\delta_{3} \text { Post }_{i, t}+X_{i, t}^{\prime} \Omega+\tau_{t}+\varepsilon_{i, t}
$$

, where $\operatorname{Tr} I n c$ is a log of monthly average household income from government cash transfer programs (unemployment compensation, industrial accident compensation, national basic livelihood security program, Veterans benefits, basic pension, and other social welfare programs) for a year preceding the survey. The first stage regression is based on the main DD specification in eq. (1), which uses the interaction term $I\left(\right.$ Age $\left._{i, t} \geq 65\right) \times$ Post $_{t}$ as an instrument. The predicted value from the first stage regression $\widehat{\operatorname{TrIn} c}$ captures variation in TrInc explained by the BP expansion and other control variables. The parameter of interest $\delta_{1}$ shows the effect of the BP expansion on health only indirectly through changes in public transfer income. As TrInc would have not changed for those not enrolled in the BP, the estimate of $\delta_{1}$ gives us net changes in health only for persons who have benefited from the BP expansion (i.e., local average treatment effect). A similar approach was used in the research of health insurance reform (Engelhardt and Gruber, 2011).

\section{Results}

Table 1 presents summary statistics by experimental conditions. On average, respondents were 61.9 years old; females made up $60 \%$ of the sample; $85 \%$ were married; and $44 \%$ were full-time employees. The average household earned 32,500 thousand KRW $(\$ 30,258)$ a year and accumulated 237,787 thousand KRW of net worth $(\$ 221,380)$. Examining the pre-post changes in health outcomes, we find that the CES-D score has fallen more significantly for the age-eligible group than for the age-ineligible group. Other health measures exhibit no significant differences by the reform across the two age groups.

[Insert Table 1 about here] 
Table 2 presents OLS estimation results for the DD models. For brevity, coefficient estimates for the fixed effects are omitted from the table. The results in columns 1 and 2 show no significant association between BP and health outcomes. The coefficients on the interaction term are small in magnitude and estimated with large standard errors, leading to no rejection of the null hypothesis. The coefficient on the interaction term in column 3 indicates that the BP expansion is associated with an average of 0.500 points decline in a mean CES-D among the age-eligible persons relative to those age-ineligible. This decline is statistically significant at the $1 \%$ level and corresponds to an $8.1 \%$ decline $(=-0.500 / 6.18)$ from its pre-2014 mean. ${ }^{7}$

[Insert Table 2 about here]

Table 3 presents coefficient estimates for eq. (2) with 2012 as a reference year. Across all three columns, the coefficient estimates on the interaction term for the years 2008 and 2010 are not significant at the $5 \%$ level (estimate of $\gamma_{3,2008}$ and $\gamma_{3,2010}$ ). The joint significance tests in the bottom panel also show no rejection of the null hypothesis that $\gamma_{3,2008}$ and $\gamma_{3,2010}$ are jointly equal to zero $\left(H_{0}: \gamma_{3,2008}=\gamma_{3,2010}=0\right)$. Combined, there is not enough evidence to reject the assumption of parallel trends in the absence of the BP expansion. Beginning in 2014, however, there is a clear trend break in the CES-D that had sustained through 2016 (column 3). The estimate of $\gamma_{3,2014}$ shows that, in the first year of expansion, the difference in the CES-D score between the age-eligible and age-ineligible groups is 0.333 units lower compared to a corresponding difference in year 2012. Evaluated at the pre-2014 mean of the CES-D, this estimate represents a $5.4 \%$ reduction in the count of depressive symptoms $(=-0.333 / 6.18)$. The estimate of $\gamma_{3,2016}$ shows 0.831 units decline (or 13.4\%) in the CES-D between 2012 and 2016 among the age-eligible group relative to the age-ineligible group.

[Insert Table 3 about here]

Fig. 1 plots coefficient estimates from Table 3. The figures on the left plot coefficient estimate on the interaction terms (solid lines) and associated 95\% confidence intervals (circles). Each point on the solid line represents difference in health between age-eligible and age-ineligible groups for each year relative to 2012. The figures on the right plot trends in health using estimates on year fixed effects and interaction terms. The first two sets of figures (grip strength and self-rated health) have relatively wide confidence intervals that include both positive and negative values and show no evidence of trend differential after the reform. The figures for the CES-D score highlight a clear trend break in 2014 and an accelerated

\footnotetext{
${ }^{7}$ The inference regarding the BP effect is robust to re-weighting regressions using the propensity score.
} 
decline in the CES-D for the age-eligible group. All figures show plausibly parallel trends in health in the pre-expansion periods.

[Insert Figure 1 about here]

The DD model rests on the assumption that unobserved factors unrelated to the BP reform are not driving trend differentials in health between the treatment and control groups. It may be of concern that unobserved policy change or macroeconomic shock occurred during or after the reform exerted differential influence on the experimental groups and contributed to a trend break in the post periods. To evaluate this possibility, we expand our DD regression with indicators of potential confounders (business cycle effect and individual/householdlevel covariates that could be affected by other policy changes) and their interactions with a treatment dummy. The additional interaction terms allow the potential confounders to have differential effects on the treatment and control groups and help $\beta_{3}$ isolate the BP's net effect.

We first present estimates from a regression with no covariates (column 1), and give baseline regression results in the next column for reference (column 2). We then add interaction terms involving a linear year variable and quadratic age effects to the baseline model (column 3). These interactions allow for differential linear and non-linear time trends in health outcomes for the treatment group relative to the younger cohorts. Next, we include all covariates in column 3 plus quarterly unemployment rate for individuals aged 55 to 64 (column 4). Unemployment rates are obtained from the Federal Reserve Economic Data at the Federal Reserve Bank of St. Louis and match-merged with the primary data according to survey dates. Lastly, we include all covariates in column 4 plus interactions between $I\left(A g e_{i, t} \geq 65\right)$ and marital status, national pension receipt, social welfare receipt, public health insurance ownership, household income, total net worth, and unemployment rate (column 5). The estimates reported in the table are coefficient estimates on the interaction term, conditioned on the baseline covariates and interaction terms.

Across all columns, the correlations between the BP expansion and the CES-D are negative and different from zero at the $5 \%$ level. The estimated coefficients vary to some degree but carry the same inference regarding the effect of the BP expansion on the CES-D. The back-of-the-envelope calculation relative to the pre-2014 mean of the CES-D ranges from $5.9 \%$ (column 4 ) to $-8.1 \%$ (column 2). The coefficient estimates from the regressions of other health outcomes are not consistently significant across specifications. Overall, we find no evidence that unobserved factors have affected the treatment and control groups differently and confounded our estimates of the BP effect in the previous analyses.

[Insert Table 4 about here] 
Next, we estimate the local average treatment effect of the BP expansion (Table 5). Column 1 presents estimates from the first stage regression, and the next three columns present second stage regression for health outcomes. Regressions control for a full set of covariates plus their interactions with a treatment dummy (as column 5 of Table 4). The first stage estimates show that the BP expansion is associated with an average of $103 \%$ increase $(=\exp (0.710)-1)$ in public transfer income among age-eligible persons relative to age-ineligible persons. The second stage estimates exhibit a 0.00542 reduction in the CES$\mathrm{D}$ for a $1 \%$ increase in public transfer income through the expansion of the BP (column 4). A rough calculation using these estimates gives us a 0.558 point decrease in the CES$\mathrm{D}$ score $(=0.00542 \times 103)$ attributable to the $\mathrm{BP}$ expansion, or a $9.0 \%$ decline from the pre-2014 mean of the CES-D $(=-0.558 / 6.18)$. This estimate is about 1.45 times larger $(=-0.558 /-0.384)$ than the corresponding interaction effect reported in Table 4 (column 5 ), confirming the prediction that age-based identification understates the policy effect by the size of unaffected individuals in the treatment group. Other health outcomes remain uncorrelated with the predicted public transfer income at the $5 \%$ level. The validity checks of the IV model reject the null hypothesis of underidentification and weak identification by a large margin.

[Insert Table 5 about here]

Lastly, we explore potential mechanisms through which pension expansion reduces depressive symptoms (Table 6). The potential mediators examined include indicators of fulltime employment, regular exercise, private health insurance ownership, out-of-pocket (OOP) expenditures for medical services, number of medical service use, subjective well-being (financial satisfaction and life satisfaction), food expenditures, and leisure expenditures (Table A2). We estimate a series of regressions that augment with these variables and examine changes in correlation between the BP reform and the CES-D score. If the BP expansion affected mental health indirectly through a particular pathway, controlling for an indicator of such would significantly attenuate the coefficient on the interaction term.

We present two sets of results: regressions in panel A test for the indirect effect through non-consumption variables, and regressions in panel B test for the indirect effect through consumption variables. The challenge of handling consumption variables in the KLoSA is that these variables capture household spending between interviews or during the year preceding the interview. As the BP effect through these consumption channels, if any, would affect mental health of the next period, regressions should model the CES-D at $t+1$ as a function of the mediator variables measured at $t+1$ and control variables at $t$. Therefore, this specification uses a smaller sample of 12,054 observations from the 2008-2014 surveys. 
We find that the coefficients on the interaction term are significantly attenuated and become statistically insignificant at the $5 \%$ level, conditional on subjective well-being (column $5)$. Other columns show the interaction effects in comparable magnitude with a high $t$-value $(p<0.05)$. This analysis, along with the supplementary regression results in Table A3, provides suggestive evidence that an increase in subjective well-being is a primary pathway the BP expansion led to fewer depressive symptoms among beneficiaries. Table A4 presents estimates from regressions of the binary indicator of clinical depression (CES-D $\geq 12$ ). It shows similar results in terms of the indirect impact of the BP expansion on mental health mediated through the subjective well-being channel. ${ }^{8}$ These additional analyses suggest that our baseline estimates are not merely picking up transient changes in depressive mood but do represent clinically meaningful improvements in mental health.

[Insert Table 6 about here]

Table 7 provides the regressions of the CES-D separately for various subsamples based on the 2012 characteristics of the respondents. The first two columns examine heterogeneity by household income and net worth, and the next three columns explore differences by gender, labor supply, and social welfare receipt. We find that the effect of the BP reform is more pronounced for females, full-time employees, and those with household income or net worth being less than the sample mean (columns 1-4). Splitting the sample by social welfare receipt confirms that the $\mathrm{BP}$ reform had no discernible influence on social welfare beneficiaries (column 5). This is consistent with the structure of the reform to transfer reduced benefits to those who were receiving supplementary income from other government programs. Overall, we see that the benefits of the BP reform accrue mostly to relatively disadvantaged households.

[Insert Table 7 about here]

\section{Conclusion}

This study examined the impact of social pension expansion on health. There are three main findings. First, we found robust evidence that the 2014 expansion of the BP was associated with improvements in mental health of beneficiaries. Our results showed an average of $8.1-9.0 \%$ reduction in the count of depressive symptoms attributable to the reform, which is in part driven by a declining prevalence of clinical depression. Second, we found suggestive evidence that improved financial satisfaction is a major pathway through which the BP

\footnotetext{
${ }^{8}$ The cut-off of 12 has been validated as a threshold for screening clinical depression among older Koreans using the CES-D10 (French et al., 2012; Lee et al., 2017).
} 
expansion produces mental health benefits. The correlations between the BP expansion and mental health became insignificant when the regressions augment with measures of financial satisfaction and life satisfaction. Third, we found no significant changes in grip strength and self-rated health. The effects of the BP on grip strength and self-rated health were generally small and not robust to alternative specifications.

It is worth noting that the mental health benefits show no evidence of fading over the time horizon for which data are available. This pattern is in contrast to the hedonic adaptation hypothesis, which suggests that the joy of economic gains gradually fades as people adapt to circumstantial changes (Frederick and Lowenstein, 1999). This might be related to the fact that the 2014 expansion of the BP was followed by a signal for additional benefit increase in the coming years. Around the time the BP was expanded, a policy direction has been set to address the problem of old-age poverty through further strengthening of non-contributory pension and social welfare programs. The reform may have incurred expectations about an additional future income from the BP, and through this expected income effect it could have compensated for declining psychological benefits over time.

An alternative explanation from a behavioral perspective is that beneficiaries would not have recognized additional cash benefits during the first few months as a permanent increase in lifetime income. The expectation that more pension will be earned during the rest of the life would be established only after beneficiaries notice an increased benefit coming repeatedly for several months. It would take a few checks to be received in order for beneficiaries to correctly perceive an increase in permanent income and to benefit from its psychological effect.

Our finding of no improvements in physical health (grip strength and self-rated health) could be related to the small amount of benefits from the BP. While Korea achieved a universal healthcare system, beneficiaries still bear high out-of-pocket expenses and often delay or forgo needed medical services over the concerns of catastrophic medical expenses (Ruger and Kim, 2007). Avoidance of healthcare due to cost-related reasons is particularly prevalent for those with multiple chronic conditions or those who need to undergo surgery or rounds of expensive treatments for an extended period. Although doubling monthly allowance was a significant improvement over its predecessor, the additional benefits from the BP might not be large enough to fulfill unmet healthcare needs. Instead, beneficiaries may have spent their pension on relatively affordable medical services, such as local clinic visits and oriental medical services, which might be beneficial for quality of life but are unlikely to improve physical strength or self-rated general health.

This study is subject to a number of limitations. First, our estimation results are subject to attrition from a sample. A positive association between health and income raises the 
concern that poor and unhealthy individuals are under-represented in our study sample and healthy individuals are over-represented. Under the plausible assumption that cash transfer would induce a greater health benefit for low-income individuals, attrition from the sample would lead to the underestimated BP effect. Second, the exclusion of smokers from the study sample could have further attenuated our estimates. As a majority of smokers could have been entitled to the BP, excluding them will omit significant health benefits among people at the lower end of the health distribution. Third, our analysis captures relatively short-term effect of the reform that arose during the first two years of implementation. Health is a stock that accumulates over time, and any positive health shock will emerge gradually. If a reduction in depressive symptoms is to have a positive spillover effect on physical health, this mechanism may take longer to observe. Lastly, despite a series of robustness checks the results are still subject to the confounding effect of concomitant policy changes that may have occurred around the reform, which are not fully observed in our biennial data. Our findings should be interpreted cautiously and put into a broader context of pension and welfare reform in Korea around mid- and late-2010s.

Despite these limitations, our findings have important implications for population health benefits of the social pension through suicide prevention. South Korea has an alarmingly high rate of elderly suicide - the highest of the OECD countries, and many older persons commit suicide due to the reasons related to financial hardship (Kwon et al., 2009). Given a strong link between depression and suicidal ideation (Shin et al., 2013), it is plausible to argue that the depression-reducing effect of pension support would have prevented premature death from suicide and produced significant mortality benefits. In the literature, correlations between non-contributory pension and improved mental health have been robust findings, reported in a range of institutional settings (Bando et al., 2016; Cheng et al., 2018; Galiani et al., 2016; Tseng and Petrie, 2014). Further study is needed to understand the association between non-contributory pension and suicide prevention among financially distressed seniors.

[Insert Table A.1 about here]

[Insert Table A.2 about here]

[Insert Table A.3 about here]

[Insert Table A.4 about here] 


\section{References}

Aguila, E., Kapteyn, A., and Smith, J. P. (2015). Effects of income supplementation on health of the poor elderly: The case of Mexico. Proceedings of the National Academy of Sciences, 112(1), 70-75.

Aguila, E., Lopez-Ortega, M., and Robledo, L. M. G. (2018). Non-contributory pension programs and frailty of older adults: Evidence from Mexico. PLoS One, 13(11), e0206792.

Bando, R., Galiani, S., and Gertler, P. (2016). The effects of non-contributory pensions on material and subjective well being (NBER Working Paper No. w22995). Cambridge, MA: National Bureau of Economic Research.

Barrientos, A., and Lloyd-Sherlock, P. (2002). Non-contributory pensions and social protection. Geneva, Switzerland: International Labour Organization.

Case, A. (2004). Does money protect health status? Evidence from South African pensions. In D. A. Wise (Ed.), Perspectives on the Economics of Aging (pp. 287-312). Chicago, IL: University of Chicago Press.

Cheng, L., Liu, H., Zhang, Y., and Zhao, Z. (2018). The health implications of social pensions: Evidence from China's new rural pension scheme. Journal of Comparative Economics, 46(1), 53-77.

Christensen, H., Mackinnon, A. J., Korten, A., and Jorm, A. F. (2001). The "common cause hypothesis" of cognitive aging: Evidence for not only a common factor but also specific associations of age with vision and grip strength in a cross-sectional analysis. Psychology and Aging, 16(4), 588-599.

Deaton, A., and Case, A. (1998). Large cash transfers to the elderly in South Africa. The Economic Journal, 108, 1330-1361.

Decker, S., and Schmitz, H. (2016). Health shocks and risk aversion. Journal of Health Economics, 50, 156-170.

Dooley, D., and Prause, J. (2002). Mental health and welfare transitions: Depression and alcohol abuse in AFDC women. American Journal of Community Psychology, 30(6), 787-813.

Engelhardt, G. V., and Gruber, J. (2011). Medicare Part D and the financial protection of the elderly. American Economic Journal: Economic Policy, 3(4), 77-102.

Frederick, S., and Loewenstein, G. (1999). Hedonic adaptation. In D. E. Kahneman, E. Diener, and N. Schwarz (Eds.), Well-being: The foundations of hedonic psychology (pp. 302-329). New York, NY: Russell Sage Foundation. 
French, D. J., Browning, C., Kendig, H., Luszcz, M. A., Saito, Y., Sargent-Cox, K., and Anstey, K. J. (2012). A simple measure with complex determinants: Investigation of the correlates of self-rated health in older men and women from three continents. BMC Public Health, 12(1), 649.

Galiani, S., Gertler, P., and Bando, R. (2016). Non-contributory pensions. Labour Economics, 38, 47-58.

Gruber, J., and Yelowitz, A. (1999). Public health insurance and private savings. Journal of Political Economy, 107(6), 1249-1274.

Hessel, P., Avendano, M., Rodríguez-Castelán, C., and Pfutze, T. (2018). Social pension income associated with small improvements in self-reported health of poor older men in Colombia. Health Affairs, 37(3), 456-463.

Hubbard, R. G., Skinner, J., and Zeldes, S. P. (1995). Precautionary saving and social insurance. Journal of Political Economy, 103(2), 360-399.

Idler, E. L., and Benyamini, Y. (1997). Self-rated health and mortality: A review of twentyseven community studies. Journal of Health and Social Behavior, 38(1), 21-37.

John, J. A., and Draper, N. R. (1980). An alternative family of transformations. Journal of the Royal Statistical Society: Series C (Applied Statistics), 29(2), 190-197.

Jones, R.S., and Urasawa, S. (2014). Reducing the high rate of poverty among the elderly in Korea (Economics Department Working Paper No. 1163). Paris, France: OECD Publishing.

Kang, S. H., and Choi, O. K. (2010). The impact of the Basic Old-Age Pension scheme on poverty reduction and income. Korea Social Policy Review, 17, 43-71.

Kaushal, N. (2014). How public pension affects elderly labor supply and well-being: Evidence from India. World Development, 56, 214-225.

Koh, K., and Yang, H. (2017). Does a government public transfer program crowd out intergenerational transfers? Evidence from South Korea. Paper presented at the Korean Association of Public Finance.

Krause, N. (1996). Welfare participation and self-esteem in later life. The Gerontologist, 36(5), 665-673.

Kuhn, A. (2018). The complex effects of retirement on health. IZA World of Labor, 430.

Kwon, J. W., Chun, H., and Cho, S. I. (2009). A closer look at the increase in suicide rates in South Korea from 1986-2005. BMC Public Health, 9, 72.

Lee, S., and Jang, H. (2015). Impact of basic senior pension on income and consumption: The regression-discontinuity approach. Journal of Governance Studies, 10, 117-142. 
Lee, S., Ku, I., and Shon, B. (2019). The effects of old-age public transfer on the wellbeing of older adults: The case of social pension in South Korea. The Journals of Gerontology: Series B, 74(3), 506-515.

Lee, C. J., and Kwon, H. J. (2016). Analysis of impacts of the basic pension: Focusing on living expenses of the elderly. Korean Public Administration Quarterly, 28, 365-388.

Lee, J., and Lee, Y. (2009). Old-age income security and private transfers in South Korea. Journal of Aging 83 Social Policy, 21(4), 393-407.

Lee, J. H., and Moon, S. (2014). The effects of basic pension on elderly consumption. Korean Policy Studies Review, 23, 411-440.

Lee, H. S., and Wolf, D. A. (2014). An evaluation of recent old-age policy innovations in South Korea. Research on Aging, 36(6), 707-730.

Lee, W., Hong, K., Lim, S. S., Kim, D. H., and Yoon, J. H. (2017). The association between symptomatic and diagnostic depression and pain among the elderly population in South Korea. The Journal of Nervous and Mental Disease, 205(9), 699-704.

Lloyd-Sherlock, P., and Agrawal, S. (2014). Pensions and the health of older people in South Africa: Is there an effect?. The Journal of Development Studies, 50(11), 1570-1586.

Pak, T. Y. (2020a). Old-age income security and tourism demand: A quasi-experimental study. Journal of Travel Research, 59(7), 1298-1315.

Pak, T. Y. (2020b). Social protection for happiness? The impact of social pension reform on subjective well-being of the Korean elderly. Journal of Policy Modeling, 42(2), 349366.

Phelan, J. C., Link, B. G., and Tehranifar, P. (2010). Social conditions as fundamental causes of health inequalities: Theory, evidence, and policy implications. Journal of Health and Social Behavior, 51(1 Suppl.), S28-S40.

Powers, E. T. (1998). Does means-testing welfare discourage saving? Evidence from a change in AFDC policy in the United States. Journal of Public Economics, 68(1), $33-53$.

Qi, D., and Wu, Y. (2018). Does welfare stigma exist in China? Policy evaluation of the Minimum Living Security System on recipients' psychological health and wellbeing. Social Science 83 Medicine, 205, 26-36.

Ruger, J. P., and Kim, H. J. (2007). Out-of-pocket healthcare spending by the poor and chronically ill in the Republic of Korea. American Journal of Public Health, 97(5), 804-811. 
Salinas-Rodríguez, A., Torres-Pereda, M. D. P., Manrique-Espinoza, B., Moreno-Tamayo, K., and Solís, M. M. T. R. (2014). Impact of the non-contributory social pension program 70 y mas on older adults' mental well-being. PLoS One, 9(11), e113085.

Shin, K. M., Cho, S. M., Hong, C. H., Park, K. S., Shin, Y. M., Lim, K. Y., et al. (2013). Suicide among the elderly and associated factors in South Korea. Aging $\& 3$ Mental Health, 17(1), 109-114.

Shin, E. H., and Do, Y. K. (2015). Basic old-age pension and financial wellbeing of older adults in South Korea. Ageing and Society, 35(5), 1055-1074.

Silventoinen, K., Magnusson, P. K., Tynelius, P., Batty, G. D., and Rasmussen, F. (2009). Association of body size and muscle strength with incidence of coronary heart disease and cerebrovascular diseases: A population-based cohort study of one million Swedish men. International Journal of Epidemiology, 38(1), 110-118.

Stuber, J., and Schlesinger, M. (2006). Sources of stigma for means-tested government programs. Social Science 83 Medicine, 63(4), 933-945.

Syddall, H., Cooper, C., Martin, F., Briggs, R., and Aihie Sayer, A. (2003). Is grip strength a useful single marker of frailty?. Age and Ageing, 32(6), 650-656.

Tseng, F. M., and Petrie, D. J. (2014). The implications for health, depression, and life satisfaction from a permanent increase in income for the disadvantaged elderly: Evidence from Taiwan. Review of Social Economy, 72(3), 311-336.

Turvey, C. L., Wallace, R. B., and Herzog, R. (1999). A revised CES-D measure of depressive symptoms and a DSM-based measure of major depressive episodes in the elderly. International Psychogeriatrics, 11(2), 139-148.

van Ginneken, W. (1999). Social security for the informal sector: A new challenge for the developing countries. International Social Security Review, 52(1), 49-69. 


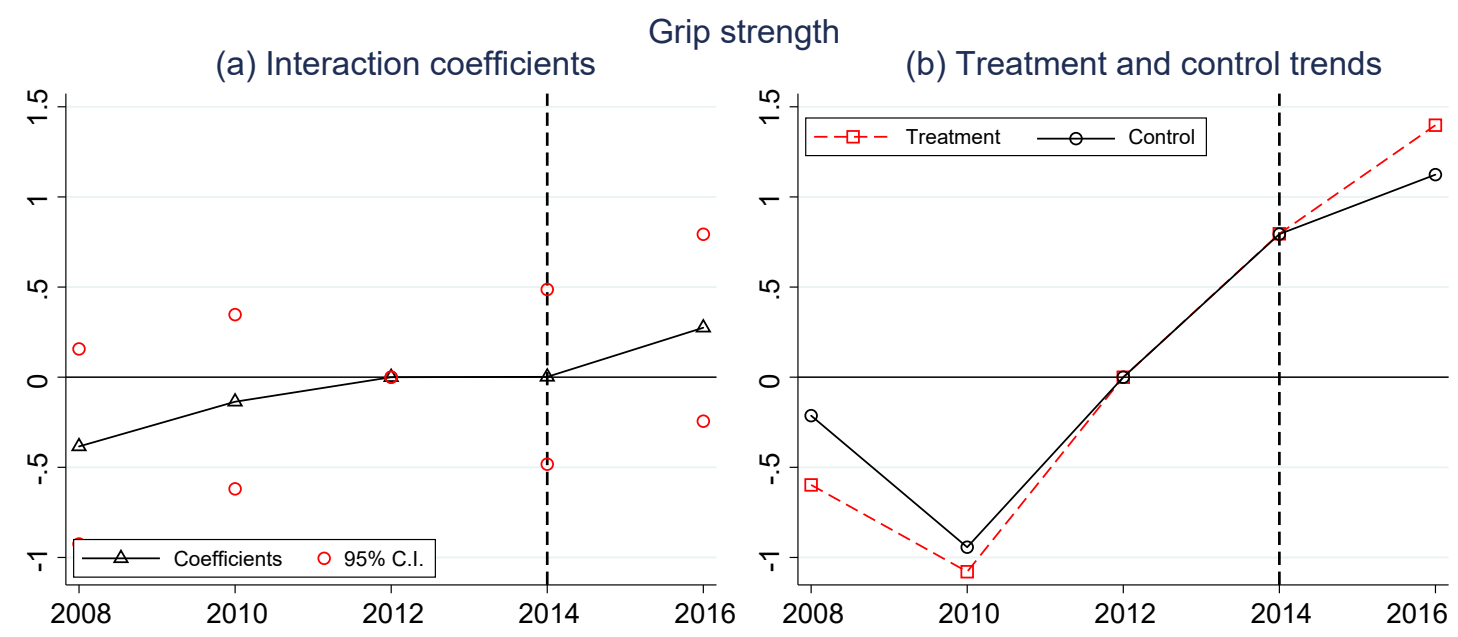

(a) Interaction coefficients

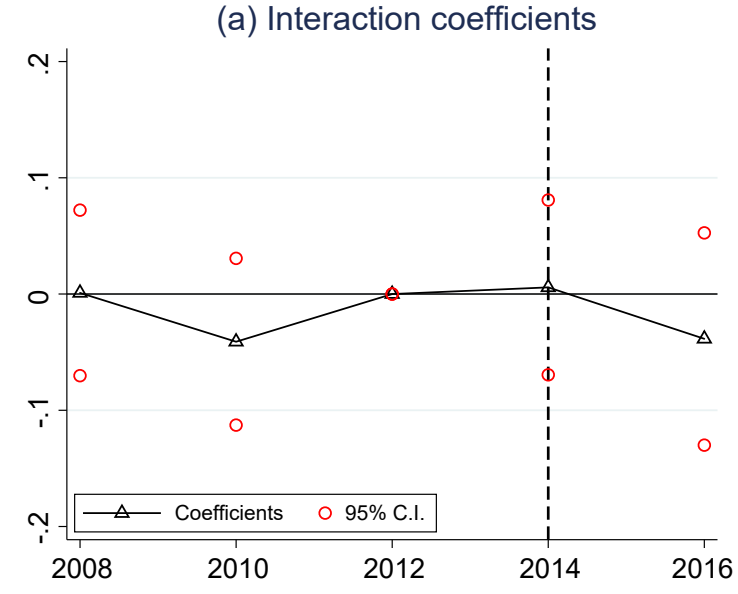

Self-rated health

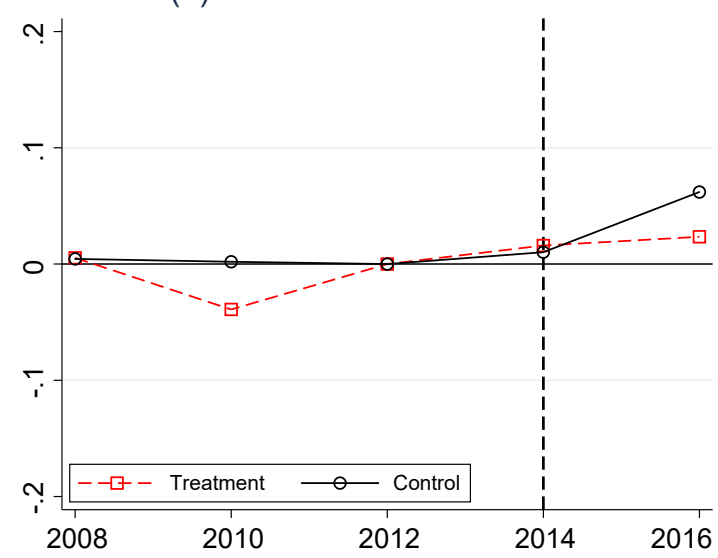

(a) Interaction coefficients

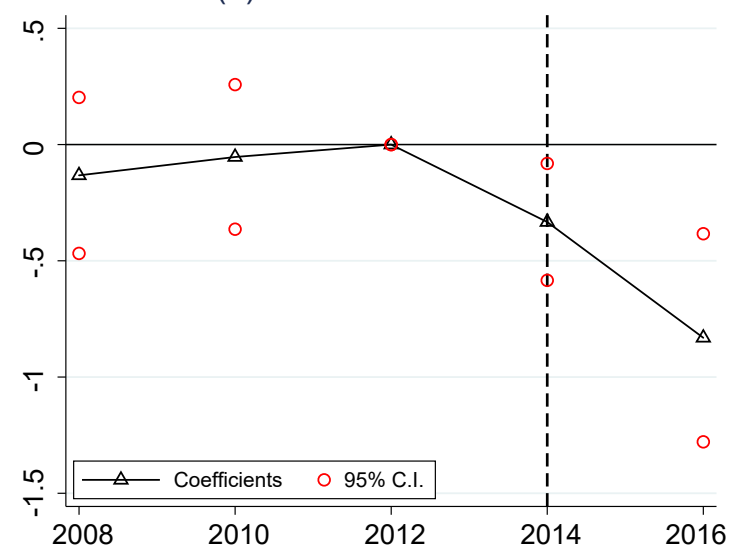

CES-D score

(b) Treatment and control trends

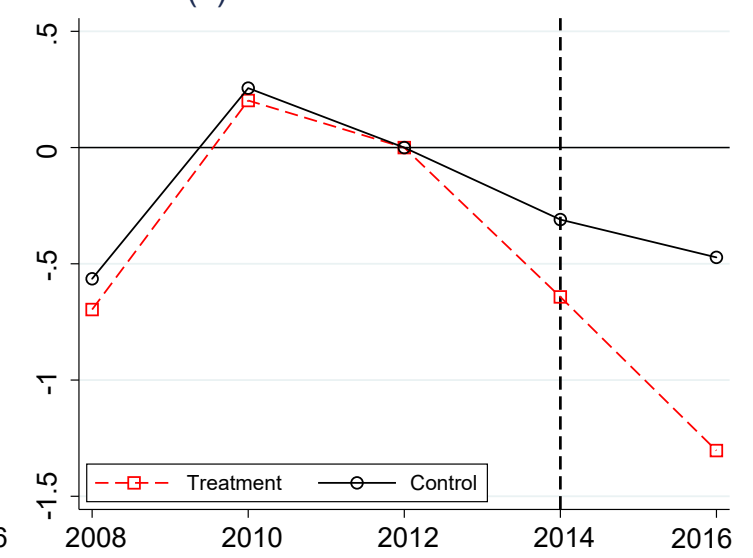

Figure 1: Event Study Plot 


\section{Tables}

Table 1: Summary statistics, KLoSA 2008-2016

\begin{tabular}{lrrrrr}
\hline \hline & Age (55-64 years) & Age $(65-74$ years) & \\
& Pre & Post & Pre & Post & Full sample \\
\hline Health outcomes & & & & & \\
Grip strength & 26.7 & 27.5 & 23.8 & 24.7 & 25.5 \\
Self-rated health (1-5) & 3.37 & 3.36 & 3.07 & 3.06 & 3.21 \\
CES-D score (0-30) & 5.68 & 5.10 & 6.79 & 5.78 & 5.93 \\
Socioeconomic covariates & & & & & \\
Age & & & & & \\
Female (0,1) & 57.0 & 59.5 & 64.4 & 67.7 & 61.9 \\
Middle school graduate (0,1) & 0.55 & 0.57 & 0.65 & 0.64 & 0.60 \\
High school graduate (0,1) & 0.22 & 0.19 & 0.19 & 0.20 & 0.20 \\
Married (0,1) & 0.54 & 0.66 & 0.33 & 0.39 & 0.47 \\
Separated or divorced (0,1) & 0.88 & 0.85 & 0.85 & 0.81 & 0.85 \\
Widowed (0,1) & 0.03 & 0.05 & 0.02 & 0.03 & 0.03 \\
Number of children & 0.08 & 0.10 & 0.12 & 0.15 & 0.11 \\
National pension beneficiary (0,1) & 2.30 & 2.15 & 2.88 & 2.67 & 2.52 \\
Social welfare beneficiary (0,1) & 0.11 & 0.13 & 0.26 & 0.34 & 0.21 \\
Own public health insurance (0,1) & 0.02 & 0.02 & 0.15 & 0.05 & 0.07 \\
Own private health insurance (0,1) & 0.98 & 0.97 & 0.95 & 0.96 & 0.96 \\
Regular exercise (0,1) & 0.54 & 0.64 & 0.29 & 0.34 & 0.44 \\
Full-time employee (0,1) & 0.44 & 0.40 & 0.41 & 0.42 & 0.42 \\
Household income (thousand KRW) & 0.55 & 0.57 & 0.33 & 0.32 & 0.44 \\
Total net worth (thousand KRW) & 37,841 & 42,257 & 25,843 & 26,230 & 32,500 \\
Financial satisfaction (0-100) & 279,712 & 190,959 & 267,028 & 168,633 & 237,787 \\
Life satisfaction (0-100) & 57.5 & 59.9 & 54.7 & 57.0 & 56.9 \\
Observations & 65.1 & 65.6 & 62.0 & 63.2 & 63.9 \\
Persons & & & & & 16,430 \\
\hline & & & & & 3792 \\
\hline
\end{tabular}

Notes: Mean values are calculated using weights provided in the KLoSA. Minimum and maximum values are presented in parentheses. ${ }^{\S}$ All monetary figures are adjusted to $2016 \mathrm{KRW}$ using the Korean consumer price index and expressed in a thousand KRW. 
Table 2: Regressions for health outcomes

\begin{tabular}{|c|c|c|c|}
\hline Outcome: & $\begin{array}{l}\text { Grip } \\
(1)\end{array}$ & $\begin{array}{c}\text { SR health } \\
(2)\end{array}$ & $\begin{array}{c}\text { CES-D } \\
(3)\end{array}$ \\
\hline$I($ Age $\geq 65)$ & $\begin{array}{c}0.002 \\
(0.157)\end{array}$ & $\begin{array}{c}0.028 \\
(0.021)\end{array}$ & $\begin{array}{c}0.292^{* *} \\
(0.138)\end{array}$ \\
\hline Post & $\begin{array}{c}1.536^{* * *} \\
(0.286)\end{array}$ & $\begin{array}{c}0.036 \\
(0.042)\end{array}$ & $\begin{array}{l}-0.065 \\
(0.305)\end{array}$ \\
\hline$I($ Age $\geq 65) \times$ Post & $\begin{array}{c}0.261 \\
(0.196)\end{array}$ & $\begin{array}{c}0.001 \\
(0.037)\end{array}$ & $\begin{array}{c}-0.500^{* * *} \\
(0.182)\end{array}$ \\
\hline Age & $\begin{array}{c}0.153 \\
(0.140)\end{array}$ & $\begin{array}{c}-0.075^{* * *} \\
(0.021)\end{array}$ & $\begin{array}{c}0.198 \\
(0.157)\end{array}$ \\
\hline Age squared (/100) & $\begin{array}{c}-0.292^{* *} \\
(0.114)\end{array}$ & $\begin{array}{l}0.044^{* *} \\
(0.017)\end{array}$ & $\begin{array}{l}-0.128 \\
(0.130)\end{array}$ \\
\hline Female & $\begin{array}{c}-12.024^{* * *} \\
(0.191)\end{array}$ & $\begin{array}{c}-0.153^{* * *} \\
(0.024)\end{array}$ & $\begin{array}{c}0.473^{* * *} \\
(0.134)\end{array}$ \\
\hline Middle school grad. & $\begin{array}{c}0.408^{* *} \\
(0.166)\end{array}$ & $\begin{array}{c}0.150^{* * *} \\
(0.028)\end{array}$ & $\begin{array}{c}-0.376^{* *} \\
(0.175)\end{array}$ \\
\hline High school grad. & $\begin{array}{c}0.671^{* * *} \\
(0.182)\end{array}$ & $\begin{array}{c}0.260^{* * *} \\
(0.028)\end{array}$ & $\begin{array}{c}-0.750^{* * *} \\
(0.166)\end{array}$ \\
\hline Married & $\begin{array}{l}2.184^{* *} \\
(0.925)\end{array}$ & $\begin{array}{c}0.099 \\
(0.112)\end{array}$ & $\begin{array}{l}-1.071 \\
(0.789)\end{array}$ \\
\hline Separated or divorced & $\begin{array}{l}2.609^{* *} \\
(1.044)\end{array}$ & $\begin{array}{c}0.052 \\
(0.122)\end{array}$ & $\begin{array}{l}-0.179 \\
(0.884)\end{array}$ \\
\hline Widowed & $\begin{array}{r}2.260^{* *} \\
(0.936)\end{array}$ & $\begin{array}{c}0.174 \\
(0.117)\end{array}$ & $\begin{array}{l}-0.327 \\
(0.803)\end{array}$ \\
\hline Number of children & $\begin{array}{c}0.037 \\
(0.077)\end{array}$ & $\begin{array}{l}-0.003 \\
(0.009)\end{array}$ & $\begin{array}{l}-0.048 \\
(0.064)\end{array}$ \\
\hline National pension & $\begin{array}{l}-0.114 \\
(0.175)\end{array}$ & $\begin{array}{l}-0.017 \\
(0.022)\end{array}$ & $\begin{array}{l}-0.119 \\
(0.174)\end{array}$ \\
\hline Social welfare & $\begin{array}{c}0.165 \\
(0.256)\end{array}$ & $\begin{array}{c}-0.118^{* * *} \\
(0.030)\end{array}$ & $\begin{array}{c}-0.601^{* *} \\
(0.237)\end{array}$ \\
\hline Public health insurance & $\begin{array}{c}1.727^{* * *} \\
(0.389)\end{array}$ & $\begin{array}{c}0.267^{* * *} \\
(0.054)\end{array}$ & $\begin{array}{c}-2.381^{* * *} \\
(0.343)\end{array}$ \\
\hline Log(HH incsome $)$ & $\begin{array}{c}0.491^{* * *} \\
(0.064)\end{array}$ & $\begin{array}{c}0.122^{* * *} \\
(0.010)\end{array}$ & $\begin{array}{c}-0.405^{* * *} \\
(0.075)\end{array}$ \\
\hline Log(net worth) & $\begin{array}{l}0.038^{* *} \\
(0.017)\end{array}$ & $\begin{array}{c}0.008^{* * *} \\
(0.002)\end{array}$ & $\begin{array}{l}-0.014 \\
(0.015)\end{array}$ \\
\hline Observations & 16,430 & 16,430 & 16,430 \\
\hline
\end{tabular}

Notes: Robust standard errors in parentheses are clustered at the individual and age levels. Regressions control for cohort fixed effects, monthof-survey fixed effects, and year-of-survey fixed effects. ${ }^{* * *} p<0.01$; ${ }^{* *}$ $p<0.05 ;{ }^{*} p<0.10$. 
Table 3: Regressions for health outcomes, with year fixed effects

\begin{tabular}{lccc}
\hline \hline Outcome: & Grip & SR health & CES-D \\
& $(1)$ & $(2)$ & $(3)$ \\
\hline I(Age $\geq 65)$ & 0.166 & $0.041^{*}$ & $0.352^{* *}$ \\
& $(0.219)$ & $(0.022)$ & $(0.144)$ \\
Year 2008 & -0.213 & 0.004 & $-0.564^{* * *}$ \\
& $(0.224)$ & $(0.032)$ & $(0.179)$ \\
Year 2010 & $-0.943^{* * *}$ & 0.002 & $0.256^{* *}$ \\
& $(0.206)$ & $(0.028)$ & $(0.128)$ \\
Year 2014 & $0.794^{* * *}$ & 0.010 & $-0.310^{* * *}$ \\
& $(0.168)$ & $(0.028)$ & $(0.108)$ \\
Year 2016 & $1.124^{* * *}$ & $0.062^{*}$ & $-0.472^{* *}$ \\
$\gamma_{3,2008}: I($ Age $\geq 65) \times$ Year 2008 & $(0.245)$ & $(0.034)$ & $(0.210)$ \\
$\gamma_{3,2010}: I($ Age $\geq 65) \times$ Year 2010 & -0.384 & 0.001 & -0.132 \\
$\gamma_{3,2014}: I($ Age $\geq 65) \times$ Year 2014 & $(0.276)$ & $(0.036)$ & $(0.171)$ \\
$\gamma_{3,2016}: I($ Age $\geq 65) \times$ Year 2016 & -0.136 & -0.041 & -0.053 \\
Observations & $(0.247)$ & $(0.037)$ & $(0.159)$ \\
Joint significance test $(p$-value from Chi-square test $):$ & & $-0.333^{* * *}$ \\
$H_{0}: \gamma_{3,2008}=\gamma_{3,2010}=0$ & 0.002 & 0.006 & $(0.128)$ \\
\hline & $(0.247)$ & $(0.038)$ & $-0.831^{* * *}$ \\
& 0.275 & -0.039 & $(0.228)$ \\
& $(0.265)$ & $(0.047)$ & 16,430 \\
& 16,430 & 16,430 & 0.742 \\
\hline
\end{tabular}

Notes: Robust standard errors in parentheses are clustered at the individual and age levels. Regressions control for cohort fixed effects, month-of-survey fixed effects, and year-of-survey fixed effects. ${ }^{* * *} p<0.01{ }^{* *} p<0.05 ;{ }^{*} p<0.10$. 
Table 4: Robustness checks

\begin{tabular}{lccccc}
\hline \hline & $(1)$ & $(2)$ & $(3)$ & $(4)$ & $(5)$ \\
\hline \multirow{2}{*}{ Grip } & 0.220 & 0.261 & -0.172 & -0.166 & -0.091 \\
& $(0.391)$ & $(0.196)$ & $(0.336)$ & $(0.324)$ & $(0.369)$ \\
SR health & 0.002 & 0.001 & 0.013 & 0.010 & 0.016 \\
& $(0.045)$ & $(0.037)$ & $(0.045)$ & $(0.044)$ & $(0.049)$ \\
CES-D & $-0.440^{* * *}$ & $-0.500^{* * *}$ & $-0.373^{* *}$ & $-0.366^{* *}$ & $-0.384^{* *}$ \\
& $(0.157)$ & $(0.182)$ & $(0.162)$ & $(0.164)$ & $(0.183)$ \\
\hline
\end{tabular}

Notes: Table presents estimates for an interaction between $I$ (Age $\geq 65$ ) and a post-2014 dummy. Column (1) presents estimates from the null model that does not control for any covariate. Column (2) shows estimates conditioned on the baseline covariates. Column (3) includes a full set of covariates plus interactions between $I$ (Age $\geq 65)$ and linear time trend and quadratic age effect. Column (4) includes all covariates in column (3) plus unemployment rate. Column (5) includes all covariates in column (4) plus interactions between $I$ (Age $\geq 65$ ) and marital status, national pension, social welfare, public health insurance, household income, total net worth, and unemployment rate. Robust standard errors in parentheses are clustered at the individual and age levels. ${ }^{* * *} p<0.01 ;{ }^{* *} p<0.05 ;{ }^{*} p<0.10$.

Table 5: Local average treatment effects

\begin{tabular}{lcccc}
\hline \hline Outcome: & $\begin{array}{c}\text { Public } \\
\text { transfer } \\
\text { income } \\
(1)\end{array}$ & Grip & SR health & CES-D \\
& $(2)$ & $(3)$ & $(4)$ \\
\hline I(Age $\geq 65) \times$ Post & $0.710^{* * *}$ & & & \\
& $(0.087)$ & & & \\
Public transfer income & & -0.128 & 0.023 & $-0.542^{* *}$ \\
& & $(0.487)$ & $(0.055)$ & $(0.258)$ \\
Underidentification $^{\mathrm{a}}$ & & 17.5 & 17.5 & 17.5 \\
Weak instruments $^{\mathrm{b}}$ & & 26.2 & 26.2 & 26.2 \\
Observations & 16,430 & 16,430 & 16,430 & 16,430 \\
\hline
\end{tabular}

Notes: Robust standard errors in parentheses are clustered at the individual and age levels. Regressions control for a full set of covariates, including interactions between $I$ (Age $\geq 65)$ and covariates. ${ }^{a}$ Kleibergen-Paap rank LM statistic tests the null hypothesis that the structural equation is underidentified (rank condition fails). ${ }^{\mathrm{b}}$ Kleibergen-Paap rk Wald statistic tests the null hypothesis of weak instruments. *** $p<0.01 ;{ }^{* *} p<0.05 ;{ }^{*} p<0.10$. 
Table 6: Evaluating potential mechanisms, CES-D score as an outcome

\begin{tabular}{|c|c|c|c|c|c|c|}
\hline \multirow[t]{2}{*}{ Outcome: } & \multicolumn{6}{|c|}{ CES-D } \\
\hline & $(1)$ & $(2)$ & $(3)$ & $(4)$ & $(5)$ & $(6)$ \\
\hline \multicolumn{7}{|l|}{ Panel A: } \\
\hline$I($ Age $\geq 65) \times$ Post & $\begin{array}{c}-0.500^{* * *} \\
(0.182)\end{array}$ & $\begin{array}{c}-0.526^{* * *} \\
(0.182)\end{array}$ & $\begin{array}{c}-0.474^{* * *} \\
(0.182)\end{array}$ & $\begin{array}{c}-0.496^{* * *} \\
(0.182)\end{array}$ & $\begin{array}{r}-0.366^{*} \\
(0.189)\end{array}$ & $\begin{array}{c}-0.380^{* *} \\
(0.187)\end{array}$ \\
\hline Full-time employee & & $\checkmark$ & & & & $\checkmark$ \\
\hline Regular exercise & & & $\checkmark$ & & & $\checkmark$ \\
\hline Own private health insurance & & & & $\checkmark$ & & $\checkmark$ \\
\hline Subjective well-being & & & & & $\checkmark$ & $\checkmark$ \\
\hline Observations & 16,430 & 16,430 & 16,430 & 16,430 & 16,428 & 16,428 \\
\hline \multicolumn{7}{|l|}{ Panel B: } \\
\hline$I($ Age $\geq 65) \times$ Post & $\begin{array}{c}-0.509^{* * *} \\
(0.188)\end{array}$ & $\begin{array}{c}-0.504^{* * *} \\
(0.187)\end{array}$ & $\begin{array}{c}-0.515^{* * *} \\
(0.187)\end{array}$ & $\begin{array}{c}-0.513^{* * *} \\
(0.187)\end{array}$ & $\begin{array}{c}-0.521^{* * *} \\
(0.187)\end{array}$ & $\begin{array}{c}-0.525^{* * *} \\
(0.185)\end{array}$ \\
\hline Full-time employee & & $\checkmark$ & & & & $\checkmark$ \\
\hline Regular exercise & & & $\checkmark$ & & & $\checkmark$ \\
\hline Own private health insurance & & & & $\checkmark$ & & $\checkmark$ \\
\hline Subjective well-being & & & & & $\checkmark$ & $\checkmark$ \\
\hline Observations & 12,054 & 12,054 & 12,054 & 12,019 & 12,054 & 12,019 \\
\hline
\end{tabular}

Notes: Robust standard errors in parentheses are clustered at the individual and age levels. Subjective well-being includes financial satisfaction and life satisfaction, defined on a scale of 0-100. Regressions control for a full set of covariates. ${ }^{* * *} p<0.01{ }^{* *} p<0.05{ }^{*} p<0.10$. 
Table 7: Heterogeneous effects by characteristics of the respondent (in 2012)

\begin{tabular}{lccccc}
\hline \hline & Income & Net worth & Female & Employed & $\begin{array}{c}\text { Social } \\
\text { welfare } \\
\text { receipt } \\
\end{array}$ \\
& $(1)$ & $(2)$ & $(3)$ & $(4)$ & $(5)$ \\
\hline Low & $-0.544^{* *}$ & $-0.884^{* * *}$ & & & \\
Observations & $(0.257)$ & $(0.336)$ & & & \\
High & 8839 & 7713 & & & \\
Observations & $-0.473^{* *}$ & -0.250 & & & \\
Yes & $(0.238)$ & $(0.240)$ & & & \\
Observations & 7591 & 8717 & $-0.675^{* *}$ & -0.252 & 0.627 \\
No & & & $(0.296)$ & $(0.306)$ & $(1.381)$ \\
& & & 10,514 & 6302 & 1474 \\
Observations & & -0.085 & $-0.647^{* *}$ & $-0.579^{* * *}$ \\
\hline
\end{tabular}

Notes: Robust standard errors in parentheses are clustered at the individual and age levels. Low values of household income are defined as household income in 2012 strictly lower than the mean of household income in 2012. Low values of net worth represent net worth in 2012 strictly lower than the median of net worth in 2012. Regressions control for a full set of covariates. ${ }^{* * *} p<0.01{ }^{* *} p<0.05$; $^{*} p<0.10$. 


\section{Appendix A}

Table A.1: Robustness of standard error estimates

\begin{tabular}{lccc}
\hline \hline Outcome: & $\begin{array}{c}\text { Grip } \\
(1)\end{array}$ & $\begin{array}{c}\text { SR health } \\
(2)\end{array}$ & $\begin{array}{c}\text { CES-D } \\
(3)\end{array}$ \\
\hline Baseline estimates & 0.261 & 0.001 & $-0.500^{* * *}$ \\
Clustered at the household and age levels & $(0.196)$ & $(0.037)$ & $(0.182)$ \\
Clustered at the household levels & $(0.256)$ & $(0.033)$ & $(0.237)^{* *}$ \\
Clustered at the age levels & $(0.183)$ & $(0.035)$ & $(0.163)^{* * *}$ \\
Clustered at the PSU levels & $(0.185)$ & $(0.029)$ & $(0.199)^{* *}$ \\
Clustered at the individual and PSU levels & $(0.188)$ & $(0.029)$ & $(0.204)^{* *}$ \\
Clustered at the individual and year levels & $(0.155)^{*}$ & $(0.027)$ & $(0.230)^{* *}$ \\
Clustered at the household and age levels & $(0.212)$ & $(0.038)$ & $(0.21)^{* *}$ \\
Clustered at the household and PSU levels & $(0.188)$ & $(0.030)$ & $(0.207)^{* *}$ \\
Clustered at the household and year levels & $(0.158)^{*}$ & $(0.027)$ & $(0.236)^{* *}$ \\
\hline
\end{tabular}

Notes: Table presents estimates for an interaction between $I$ (Age $\geq 65$ ) and a post-2014 dummy. Robust standard errors in parentheses. Regressions control for a full set of covariates. ${ }^{* * *} p<0.01$; $^{* *} p<0.05$; $^{*} p<0.10$.

Table A.2: Description of covariates

\begin{tabular}{|c|c|}
\hline Variable & Description \\
\hline Full-time employee & Respondent is paid-employee or self-employed. \\
\hline Regular exercise & Respondent does exercise at least once a week. \\
\hline Private health insurance & $\begin{array}{l}\text { Respondent owns private health insurance, not including life } \\
\text { insurance. }\end{array}$ \\
\hline Financial satisfaction & $\begin{array}{l}\text { Response on a range of } 0-100 \text { to "how happy are you with your } \\
\text { financial condition?" }\end{array}$ \\
\hline Life satisfaction & $\begin{array}{l}\text { Response on a range of 0-100 to "how satisfied are you with your } \\
\text { overall quality of life?" }\end{array}$ \\
\hline Number of medical service use & $\begin{array}{l}\text { Number of inpatient and outpatient care use, dental visit, and } \\
\text { oriental clinic visit since the last survey. }\end{array}$ \\
\hline OOP medical expenditures & $\begin{array}{l}\text { Out-of-pocket expenditures for inpatient and outpatient care, } \\
\text { dental care, oriental medical services, and prescription drugs } \\
\text { since the last survey. }\end{array}$ \\
\hline Food expenditures & $\begin{array}{l}\text { Monthly average spending on food-at-home and } \\
\text { food-away-from-home in the year prior to the survey. }\end{array}$ \\
\hline Leisure expenditures & $\begin{array}{l}\text { Monthly average spending on leisure trips (tour, journey, and } \\
\text { picnic), entertainment activities (attending arts, cultural, sports, } \\
\text { and other entertainment events), and recreational activities } \\
\text { (participation in hobby/recreation-related activities or programs) } \\
\text { over the last } 12 \text { months before the survey. }\end{array}$ \\
\hline
\end{tabular}


Table A.3: Robustness of standard error estimates

\begin{tabular}{lcc}
\hline \hline Outcome: & Financial satisfaction & Life satisfaction \\
& $(1)$ & $(2)$ \\
\hline$I($ Age $\geq 65) \times$ Post & $1.986^{* * *}$ & $1.309^{*}$ \\
& $(0.697)$ & $(0.680)$ \\
Observations & 16,428 & 16,428 \\
\hline
\end{tabular}

Notes: Robust standard errors in parentheses are clustered at the individual and age levels. Regressions control for a full set of covariates. ${ }^{* * *} p<0.01 ;{ }^{* *} p<0.05 ; * p<0.10$.

Table A.4: Evaluating potential mechanisms, clinical depression as an outcome

\begin{tabular}{|c|c|c|c|c|c|c|}
\hline \multirow[t]{2}{*}{ Outcome: } & \multicolumn{6}{|c|}{ Clinical depression (CES-D $\geq 12$ ) } \\
\hline & $(1)$ & $(2)$ & $(3)$ & $(4)$ & $(5)$ & $(6)$ \\
\hline \multicolumn{7}{|l|}{ Panel A: } \\
\hline$I($ Age $\geq 65) \times$ Post & $\begin{array}{c}-0.030^{* *} \\
(0.012)\end{array}$ & $\begin{array}{c}-0.031^{* * *} \\
(0.012)\end{array}$ & $\begin{array}{c}-0.029^{* *} \\
(0.012)\end{array}$ & $\begin{array}{c}-0.030^{* *} \\
(0.012)\end{array}$ & $\begin{array}{c}-0.024^{*} \\
(0.013)\end{array}$ & $\begin{array}{c}-0.024^{*} \\
(0.013)\end{array}$ \\
\hline Full-time employee & & $\checkmark$ & & & & $\checkmark$ \\
\hline Regular exercise & & & $\checkmark$ & & & $\checkmark$ \\
\hline Own private health insurance & & & & $\checkmark$ & & $\checkmark$ \\
\hline Subjective well-being & & & & & $\checkmark$ & $\checkmark$ \\
\hline Observations & 16,430 & 16,430 & 16,430 & 16,430 & 16,428 & 16,428 \\
\hline \multicolumn{7}{|l|}{ Panel B: } \\
\hline$I($ Age $\geq 65) \times$ Post & $\begin{array}{c}-0.039 * * * \\
(0.013)\end{array}$ & $\begin{array}{c}-0.039^{* * *} \\
(0.013)\end{array}$ & $\begin{array}{c}-0.039^{* * *} \\
(0.013)\end{array}$ & $\begin{array}{c}-0.038^{* * *} \\
(0.013)\end{array}$ & $\begin{array}{c}-0.040^{* * *} \\
(0.014)\end{array}$ & $\begin{array}{c}-0.040^{* * *} \\
(0.014)\end{array}$ \\
\hline Full-time employee & & $\checkmark$ & & & & $\checkmark$ \\
\hline Regular exercise & & & $\checkmark$ & & & $\checkmark$ \\
\hline Own private health insurance & & & & $\checkmark$ & & $\checkmark$ \\
\hline Subjective well-being & & & & & $\checkmark$ & $\checkmark$ \\
\hline Observations & 12,054 & 12,054 & 12,054 & 12,019 & 12,054 & 12,019 \\
\hline
\end{tabular}

Notes: Robust standard errors in parentheses are clustered at the individual and age levels. Subjective well-being includes financial satisfaction and life satisfaction, defined on a scale of 0-100. Regressions control for a full set of covariates. ${ }^{* * *} p<0.01 ;{ }^{* *} p<0.05 ;{ }^{*} p<0.10$. 